\title{
Statistical analysis for the impact of smoking on the behavior and health of Qatari adolescents
}

\author{
${ }^{1}$ Department of Mathematics, Statistics and Physics, College of Arts and Science, Qatar University, Doha, Qatar, E-mail: \\ abdo@qu.edu.qa
}

\begin{abstract}
:
The links between the use of tobacco and health risks are well known. Most of the younger smokers reside in Asia which includes Qatar, the focus country of this study. Cigarette smoking among children is rising at an alarming rate worldwide including Qatar. As youth make up a significant percentage of the population and to achieve the health objectives of the Qatar Vision 2030, it is essential to ensure the health and well-being of adolescents, as they are the future of Qatar. This study focuses on exploring the patterns of tobacco use and its impacts on the adolescents by conducting a survey in different schools across Qatar. The questionnaire was administered in five schools, selected by proportional random sampling. The responses were recorded from the sample for general questions regarding interest in physical activities, relationship with family and friends, mental satisfaction, health, academics and access to cigarettes.
\end{abstract}

Keywords: adolescents, logistic regression, modelling techniques, non-parametric tests, Qatar, smoking DOI: $10.1515 /$ ijamh-2018-0045

Received: February 24, 2018; Accepted: April 10, 2018

\section{Introduction}

The inhalation of the smoke of burning tobacco in cigarettes, pipes and cigars is known as smoking. Smoke contains about 4000 poisonous chemicals, including cancer-causing nicotine, tar and carbon monoxide, ammonia and hydrogen cyanide. Smoking is an addictive habit that has far reaching adverse effects on health, including mental and physical health. According to the Centers for Disease Control and Prevention [1] and [2] "students who smoke are also more likely to use other drugs, get into fights, carry weapons and attempt suicide".

Most adults often start smoking in adolescence. Young adults are impressionable and can be affected by factors such as peer pressure, curiosity, "the feel-good syndrome" or just a lack of awareness by adults which makes them pick up the habit of smoking. Adolescence is a sensitive period in which the children go through significant developments. The changes occurring during this critical stage of life can be considered as the most vulnerable period for smoking initiation amongst children [3]. Many children at this age briefly acknowledge the fact that smoking could be addictive, second-hand smoke can cause harm, or that smoking leads to many health problems [4]. Usually, smoking is a way for these children to avoid unpleasant emotions such as stress or to just look cool or mature. Another major reason why smoking is gaining popularity in children is due to cigarettes being readily available almost everywhere in Qatar at comparatively low prices.

Smoking anticipations/expectancies in youth can be assessed most reliably in the early school years of the children [3]. According to Kimberly Kobus's study [5] children tend to become members of a large group to arrive at favorable definitions of identity. Thus, trying cigarettes becomes frequent as the child attempts to avoid possible exclusion by peers and to gain social approval. Apart from this, social crowds, best friends, peer groups and romantic partners have all been found to contribute to the behaviors of smoking in adolescents [5].

As the influence of smoking goes from adolescent to adulthood years; it implies that this extended period of smoking will eventually lead to the development of chronic health issues [6]. Many studies have been conducted to find the relationship between tobacco use and its impact on health. The study of distinguishing risk factors for the onset of cravings, withdrawal symptoms and tolerance in novice adolescent smokers, found that smoking causes physical and psychological symptoms such as insomnia, anger, anxiety, depression and eating disorders [7]. Besides this, in Bewley and Bland's research [8] the academic performance of school children was measured with their smoking behavior. The children were asked to evaluate their academic performance, and then the teachers were invited to assess them as well. They found that more non-smokers said their work was good in comparison to the smokers; the difference was more significant for the boys. Then the teachers were asked to 
classify the same students academically. The results showed a significant relationship between how the teachers perceived the students and how the students rate themselves. If the teachers viewed them as academically inferior, the student also observed him/herself in a similar way. Undeniably, the aim of these studies showed the importance of the role of a teacher in shaping a child's psyche and how the children eventually view themselves.

Understanding the early adolescent smoker is very crucial to developing a preventative strategy. The studies mentioned above, as well as other research, show that adolescent smoking is due to various factors which eventually lead to health problems in the later life of the smoker. Adolescent smoking has become a serious issue in Qatar. On average, children (boys and girls) in Qatar smoke more than children in other countries [9]. Intriguingly, it has been found that the most common age for children to start experimenting with cigarettes is $12-13$ years and $90 \%$ of adult smokers have their first cigarette when they were children [10], [11]. In Qatar, easy access to cigarettes (ACC) from an early age is a major factor that encourages smoking among adolescents. Moreover, flavored cigarettes have been introduced that children find more attractive and even consider them less harmful, which is not the case. Most developed countries have smoking helplines especially dedicated to those who want to quit smoking, which is not the case in Qatar.

The youth make up a significant percentage of the Qatari population, and it is essential to ensure the health and well-being of the youth for the future of Qatar and to achieve the health objectives of Qatar Vision 2030. Studies focusing on children who smoke have been conducted in other countries, but little is known about the extent of smoking in Qatar's school and its impact on health or behavior on Qatar's students. Ideally a longitudinal study design is appropriate to investigate the dynamic social behavior [12]. This study presented herein however can be taken as an initial step to explore relationships between adolescence smoking behavior, education and health; regardless of their previous smoking behavior. This study aims to explore the adolescent smoking patterns in Qatar.

\section{Materials and methods}

This was a prospective cohort study for understand the relationship between behavior, academic and health aspects of adolescent smoking. The target population of this study was the students from grade 7 to 12 , both boys and girls. The reason for choosing this particular age group was because they fall under the category of adolescents as per Global School-based Student Health Survey (GSHS) 2011 data. It is known that during these years of a person's life there is a high chance of initiating smoking; therefore, it is important to highlight the negative effects smoking has on a child at this age. The survey was conducted to focus on three important factors in this study: behavior, academics and health aspects, in association with smoking. Five different schools in Qatar were chosen by proportional random sampling [13], which included both the public and private schools.

The responses were recorded from a sample of 350 students. The survey also aimed to have a balanced number of Qataris and non-Qataris; however, the final results included 110 Qatari respondents and 240 nonQataris. This was due to some problems that were encountered during the distribution of the survey among schools as some schools declined to take part in research which was related to smoking. This setback occurred when public schools were asked to participate in the survey, where the majority of the students were Qatari. This problem also occurred in all girls' schools as they were not ready to take part in this 'taboo' research which involved girls and smoking. As a result, the response from the private schools was greater than the public schools; as 226 survey responses were collected from private schools in comparison to the 124 public schools' surveys.

Despite the efforts to balance the number of male and female respondents, the female respondents outnumbered the males; as 197 females responded, while only 153 males responded to the survey. As per statistical profile for women and men in the year 2014, the ratio for Qatari females to males is 1.04 and for non-Qataris it is 0.81 for the ages above 15. However, for our sample the female/male ratio is 3.41 for Qataris and 0.88 for nonQataris; which matches for the non-Qatari population but not for the Qatari. The reason could be that lesser Qatari respondents appeared overall as compared to non-Qatari respondents.

To reach the aims of this research, several statistical techniques were used; starting with descriptive analysis and testing for association to the regression analysis. The descriptive analysis was performed to obtain an overview of the responses recorded. Chi-squared $\left(\chi^{2}\right)$-tests were carried out to test the association between smoking status and student grades, family history and feeling lonely. Factor analysis was carried out prior to the logistic regression analysis, to avoid possible multi-collinearity problem; as a 50-item questionnaire was used for survey. 


\section{Results and discussions}

The overall smoking prevalence was $25 \%$ (87 students), where a cumulative of $95.7 \%$ tried smoking before the 14 years of age. The male students were proportionally more likely to be smokers, $37.91 \%(58)$ in comparison with female students, $14.7 \%$ (29). The proportion of smokers in primary school $12.03 \%$ (16), was less than the proportion smokers in secondary school $32.72 \%$, (71) as per the total students in primary and secondary schools.

Most of the non-Qatari students $30.0 \%$ (72) in the sample reported themselves as smokers as compared to Qataris 13.6\%. For understanding students' physical activities (PA), they were asked, "how actively they had participated and performed in school in the last 6 months" before the study. The results showed that $27.6 \%$ of the students went out with family while $25 \%$ of the students played computer or video games. However, only $6.22 \%$ of the students took part in school clubs. The detailed responses recorded from survey are shown in Figure 1. In addition, when children from both public and private schools were asked "if they had seen an anti-smoking campaign at school or their city", only $5.4 \%$ answered to have seen the campaign at their school, $15.4 \%$ had seen it at their school as well as in the city, while $29.1 \%$ of the pool answered that they had never seen an anti-smoking campaign (see Figure 2).

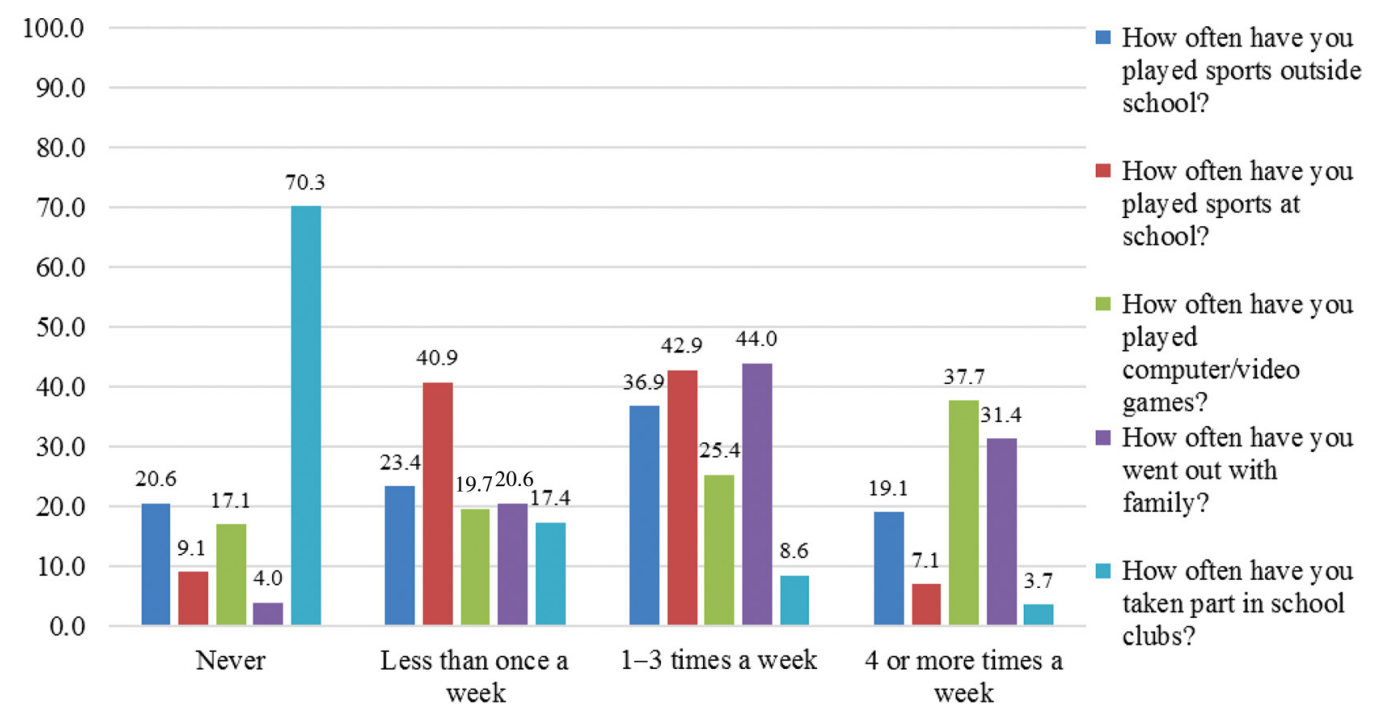

Figure 1: Student activities in the last 6 months.

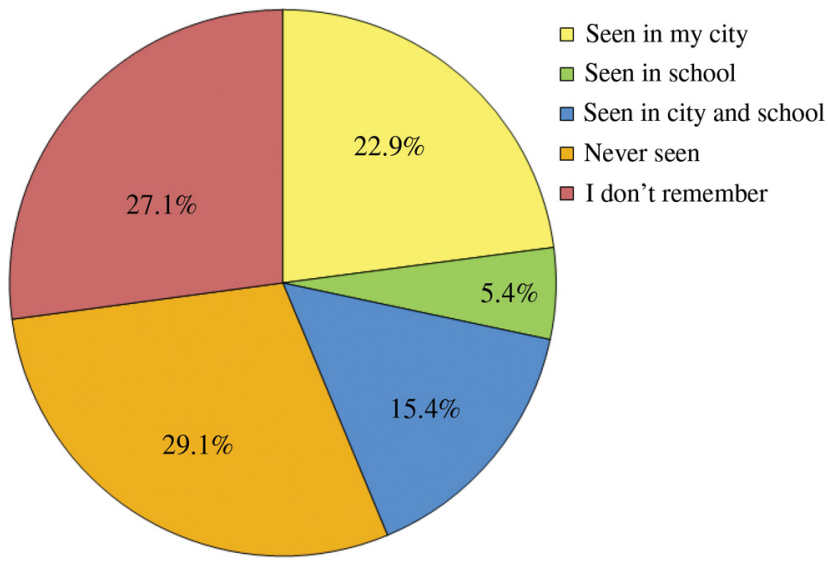

Figure 2: Anti-smoking campaigns.

The $\chi^{2}$-test of independence was calculated to the association between smoker status (Yes/No) and student grades, family history and feeling lonely. A significant interaction was found between the students' school grades and smoking status $\left[\chi^{2}(1)=6.181, p<0.05\right]$. In addition, $\chi^{2}$-test shows that there is statistically significant association between the children who have ever tried smoking to the smoking of one or both parents $\left[\chi^{2}(3)=\right.$ $37.53, \mathrm{p}<0.05]$. Furthermore, there is a statistically significant association between smoking and feeling lonely $\left[\chi^{2}(1)=4.12, \mathrm{p}<0.05\right]$. A significant association is found between smoking status and gender, nationality, class with $\mathrm{p}<0.05$.

Chua (2009) recommended factor analysis as one method used by researchers to classify, organize and reduce a large number of inter-correlated variables into a new factor represented by an appropriate linear com- 
bination of these inter-correlated variables [14]. The reliability statistic, Cronbach's $\alpha$, was examined at the first step to include only highly correlated variables in the factor analysis. The Kaiser-Meyer-Olkin test for sampling adequacy was 0.757, (higher than recommended 0.60), showing that the sample is adequate for performing factor analysis. The scree plot suggested selecting five factors explaining $61.13 \%$ of the total variability in the dataset.

From the factor loading matrix (Table 1), the inter-correlated variables in factor 1 explain the overall ACC for respondents in Qatar. The group motivation (GM) is considered as a trigger to try smoking by the motivation from the fellows of same age group. Students' social attitude (SA) was assessed by their behavior towards involvement in fights and the relationship with their peer group for getting injured or bullied. Factor 4 was named as students' closeness to family (CF) which was formed by items on relations with family. Only two items could adequately explain the student's PA in past 6 months which is factor 5. Other variables including awareness about anti-smoking campaigns, health impact, and family history of smoking could not be grouped together because of difference in response scale.

Table 1: Factor loading matrix.

\begin{tabular}{|c|c|c|}
\hline & Loading $^{\mathrm{a}}$ & Communality $^{b}$ \\
\hline \multicolumn{3}{|l|}{ Factor 1. ACC - access to cigarettes $(\alpha=0.779)$} \\
\hline $\begin{array}{l}\text { How easy or difficult do you think it would be for you if you wanted to hide } \\
\text { cigarettes at home? }\end{array}$ & 0.675 & 0.507 \\
\hline Has anyone in a store ever refused to sell you cigarettes? & 0.788 & 0.698 \\
\hline Have you ever been asked your age when buying cigarette at a store? & 0.817 & 0.715 \\
\hline Is it easy for you to buy cigarettes in Qatar? & 0.702 & 0.501 \\
\hline \multicolumn{3}{|l|}{ Factor 2. GM - group motivation $(\alpha=0.678)$} \\
\hline Does anyone in your age group smoke? & 0.846 & 0.772 \\
\hline Does anyone in your age group who smokes display any of these behaviors? & 0.857 & 0.767 \\
\hline Have you ever tried smoking? & 0.561 & 0.658 \\
\hline \multicolumn{3}{|l|}{ Factor 3. SA - student's social attitude $(\alpha=0.618)$} \\
\hline In last 6 months, how many times you were involved in a physical fight? & 0.753 & 0.705 \\
\hline In last 6 months, how many times you were injured in a fight? & 0.795 & 0.732 \\
\hline In last 6 months, how many times you were bullied? & 0.683 & 0.582 \\
\hline \multicolumn{3}{|l|}{ Factor $4 . \mathrm{CF}-$ student's closeness to family $(\alpha=0.432)$} \\
\hline How often have you go out with family? & 0.497 & 0.339 \\
\hline How close are you to your parents? & 0.607 & 0.476 \\
\hline Do you try talking to a friend/parent/sibling when you feel lonely? & 0.667 & 0.454 \\
\hline \multicolumn{3}{|l|}{ Factor 5. PA - student's physical activities $(\alpha=0.376)$} \\
\hline How often have you played sports outside school? & 0.768 & 0.613 \\
\hline How often have you played computer/video games? & 0.719 & 0.550 \\
\hline
\end{tabular}

${ }^{a}$ Is the strong of the association between each variable in the factor analysis and the underlying factor. ${ }^{\mathrm{b}}$ Is the proportion of each variable's variance that can be explained by each underlying factor.

For modeling the smoking behavior of the adolescents, which is a dichotomous variable (smoker/nonsmoker, as per the question "Have you ever tried smoking?"), a logistic regression analysis was carried out [15]. The logistic regression model with "forward selection" was performed using the five factors resulting from the factor analysis plus other selected variables (including demographics) for predicting the smoking behavior of adolescents. The dependent variable was "smoker/non-smoker" and the independent variables include the five factors with some other social and economic variables significantly associated (per crosstabs) with the smoking status; age, gender, nationality, class, parents' smoking, satisfaction from educational performance and health warnings on cigarettes. The model selection summary (Table 2) shows the step-wise entry of significant variables in the model where ACC, GM and SA represent the factors. The final model at step 6 containing only the significant variables is presented.

Table 2: Smoking behavior (logistic regression results).

\begin{tabular}{|c|c|c|c|c|c|c|c|c|}
\hline \multirow[t]{2}{*}{ Step } & \multicolumn{3}{|c|}{ Improvement } & \multicolumn{3}{|c|}{ Model } & \multirow[t]{2}{*}{ Correct class \% } & \multirow[t]{2}{*}{ Variable } \\
\hline & $\chi^{2}$ & df & Sig. & $\chi^{2}$ & df & Sig. & & \\
\hline \multicolumn{9}{|c|}{ Model selection summary } \\
\hline 1 & 113.516 & 1 & 0.000 & 113.516 & 1 & 0.000 & $78.0 \%$ & IN: ACC \\
\hline 2 & 92.016 & 3 & 0.000 & 205.532 & 4 & 0.000 & $84.0 \%$ & IN: health \\
\hline 3 & 64.246 & 1 & 0.000 & 269.778 & 5 & 0.000 & $87.1 \%$ & IN: GM \\
\hline
\end{tabular}




\begin{tabular}{|c|c|c|c|c|c|c|c|c|c|c|}
\hline $\begin{array}{l}4 \\
5 \\
6\end{array}$ & $\begin{array}{r}15.707 \\
10.936 \\
4.367\end{array}$ & $\begin{array}{l}1 \\
2 \\
1\end{array}$ & $\begin{array}{l}0.000 \\
0.004 \\
0.037\end{array}$ & $\begin{array}{l}285.485 \\
296.421 \\
300.788\end{array}$ & $\begin{array}{l}6 \\
8 \\
9\end{array}$ & $\begin{array}{l}0.000 \\
0.000\end{array}$ & & $\begin{array}{l}\text { IN: } \\
\text { IN: } \\
\text { IN: }\end{array}$ & $\begin{array}{l}\text { ats } \\
\text { ation sa }\end{array}$ & action \\
\hline & & & & & B & S.E. & Wald & df & Sig. & $\operatorname{Exp}(B)$ \\
\hline \multicolumn{11}{|c|}{ Variables in the equation } \\
\hline \multirow[t]{12}{*}{ Step 6} & \multicolumn{4}{|c|}{$\mathrm{ACC}$} & -2.048 & 0.252 & 65.803 & 1 & 0.000 & 0.129 \\
\hline & \multicolumn{4}{|l|}{ GM } & -1.384 & 0.200 & 47.802 & 1 & 0.000 & 0.251 \\
\hline & \multicolumn{4}{|c|}{ SA } & -0.629 & 0.193 & 10.663 & 1 & 0.001 & 0.533 \\
\hline & \multicolumn{4}{|c|}{ Parents } & & & 10.104 & 2 & 0.006 & \\
\hline & \multicolumn{4}{|c|}{ P1. Father smokes } & 0.368 & 0.461 & 0.638 & 1 & 0.424 & 1.445 \\
\hline & P2. I & par & ats smoke & & 1.941 & 0.611 & 10.104 & 1 & 0.001 & 6.968 \\
\hline & \multicolumn{10}{|c|}{ Education satisfaction } \\
\hline & E1: I & & & & 0.951 & 0.456 & 4.362 & 1 & 0.037 & 2.589 \\
\hline & \multicolumn{4}{|c|}{ Health } & & & 51.539 & 3 & 0.000 & \\
\hline & \multicolumn{4}{|c|}{ H1. Yes } & -2.223 & 0.353 & 39.751 & 1 & 0.000 & 0.108 \\
\hline & \multicolumn{4}{|c|}{$\mathrm{H} 2 . \mathrm{No}$} & -3.093 & 0.732 & 17.870 & 1 & 0.000 & 0.045 \\
\hline & \multicolumn{4}{|c|}{ H3. I don't know } & -3.186 & 0.688 & 21.431 & 1 & 0.000 & 0.041 \\
\hline
\end{tabular}

Nagelkerke's R square:76.9\%. Hosmer and Lemeshow's test: $\chi^{2}(8)=71.868$, p-value $=0.000$.

Based on p-values for model selection, a significant improvement in the model is observed by adding variables. The logistic regression model (see Table 2) correctly classified the outcome for $89.1 \%$ of the cases compared to $24.9 \%$ correctly classified by the null model. The estimated coefficients from the logistic regression (see Table 2) indicate a statistically significant effect of the three factors (ACC, GM, student's SA), the effect of parents' smoking, satisfaction from educational performance, and health warnings on cigarettes on the smoking behavior, regardless of demographic differences. However, the negative effects of ACC, GM and involvement in social activities are observed. The children of parents who smoke are more likely to smoke. The students who are less satisfied with their educational performance at school are more likely to smoke. The students believing in health warnings on cigarettes are less likely to smoke as compared to the ones who do not even look at those warnings. Also, the ones who classify themselves as non-believers or are unsure about health warnings, are also less likely to smoke as compared to those not reading the health warnings.

To predict the academic performance (Good/Poor) of students, the sum of the basic academic questions asked in the survey were combined and a logistic regression was carried out. The dependent variable was named as the student's educational effect (Good/Poor) and the independent variables included all the factors obtained from factor analysis and the selected variables (age, gender, grade and nationality).

From Table 3, one can see that, the positive effects of ACC and SA on academic performance are counter intuitive: per the results, as ACC (ease of getting cigarettes and hiding them at home) and students' involvement in unwanted social activities increase, the odds of a student having good performance will increase by 1.528 and 1.490 times, respectively. Per the results, those who classified themselves as Qatari, are less likely to perform better academically as compared to non-Qatari students.

Table 3: Academic performance (logistic regression results).

\begin{tabular}{|c|c|c|c|c|c|c|c|c|c|c|c|}
\hline \multirow[t]{2}{*}{ Step } & \multicolumn{3}{|c|}{ Improvement } & \multicolumn{3}{|r|}{ Model } & \multicolumn{2}{|c|}{ Correct class, $\%$} & \multicolumn{3}{|c|}{ Variable } \\
\hline & $\chi^{2}$ & df & Sig. & $\chi^{2}$ & df & Sig. & & & & & \\
\hline \multicolumn{12}{|c|}{ Model selection summary } \\
\hline 1 & 13.063 & 1 & 0.000 & 13.063 & 1 & 0.000 & & $73.7 \%$ & \multicolumn{3}{|c|}{ IN: Nationality } \\
\hline 2 & 11.352 & 1 & 0.001 & 24.416 & 2 & 0.000 & & $73.7 \%$ & \multicolumn{2}{|c|}{ IN: ACC } & \\
\hline \multirow[t]{2}{*}{3} & 9.388 & 1 & 0.002 & 33.803 & 3 & 0.000 & & $72.3 \%$ & \multicolumn{2}{|c|}{ IN: SA } & \\
\hline & & & & B & & S.E. & Wald & & & Sig. & $\operatorname{Exp}(B)$ \\
\hline \multicolumn{12}{|c|}{ Variables in the equation } \\
\hline \multirow[t]{4}{*}{ Step 3} & ACC & & & 0.424 & & 0.123 & 11.824 & & 1 & 0.001 & 1.528 \\
\hline & SA & & & 0.399 & & 0.132 & 9.086 & & 1 & 0.003 & 1.490 \\
\hline & \multicolumn{3}{|c|}{ Nationality } & & & & & & & & \\
\hline & N1 & tari & & -1.172 & & 0.272 & 18.518 & & 1 & 0.000 & 0.310 \\
\hline
\end{tabular}

Nagelkerke's R square: $13.5 \%$. Hosmer and Lemeshow's test: $\chi^{2}(8)=6.226$, p-value $=0.622$. 
Based on the results from our sample, the adolescents in Qatar having easy ACC, motivation from peer group, or tendencies to involve in fights or being bullied are less likely to smoke. These results however turned out to be in contradiction with the expected outcomes, but are in partial accordance with the results from Bewley and Bland's research [8]. As the questionnaire was used to collect self-reporting data from a cross-section of students, they might not want to report themselves as "smokers" or "poor performers". The data supports this doubt, where only $24.9 \%$ of the students reported themselves as smokers, while the remaining $75.1 \%$ claim not to be smokers. In addition, $73.7 \%$ of the students fall in the category of academically performing well as per their responses. However, the cross tabulation highlighted that $79 \%$ of the non-smokers rated themselves as good performers, as compared to $57 \%$ who were smokers and good performers.

A high number of female respondents (56.3\%) may also be one of the reasons for having unexpected results, as the tendency of smoking is usually found to be high in boys. The mixed results may also be triggered from the population distribution in Qatar; as the Qatari population is a mix of cultures due to a high percentage of expatriates. The sample constitutes of $68.6 \%$ non-Qatari and 31.4\% Qatari students. The trend towards smoking is found to be on rise in the non-Qatari students as compared to Qataris as per the percentage within each category and results from crosstabs; 30\% non-Qatari smokers, as compared to 13.6\% of Qatari smokers. The results showed that reading the health warnings on cigarette packets is an important aspect for the students to try restricting them from smoking. The remaining part, i.e. making them to believe in those warnings can further add a significant value to decrease smoking, which is mainly the responsibility of parents and school. $\mathrm{CF}$ and remaining physically active are indifferent for explaining the smoking behavior of students.

\section{Conclusion}

This study estimates the prevalence in relation to the age at first cigarette matches with the results from GSHS data [10] as $95.7 \%$ in comparison to $93.5 \%$; minor differences can be regarded as being due to the difference in sample size. The descriptive statistics showed that most of the adolescents attending school in Qatar are unaware of anti-smoking campaigns and thus the dangers associated with it. Most of the students agreed that they did not see any student smoking inside the school. However, a significant association between the two suggests that still there can be pressure from peer groups of looking cool or mature by smoking. Most of the students in the sample turned out to be not regular smokers. Rather, they smoked once or plan to smoke in future (as per self-reporting). However, the ones who even tried one cigarette are rated as "smokers" because that activity usually becomes a first step towards regular smoking.

From an academic perspective, it is found that the students who do not smoke perform academically better as compared to the ones who do. Also, the pressure from peer group and involvement in social activities turned out to be associated with non-smoking behavior and good academic performance.

It is recommended that the results of this study be used as an initial step towards exploring the relationships between smoking, behavior, academics and health of adolescence in Qatar. Future studies may use a longitudinal study design to investigate the impact of smoking among adolescence. In addition, because of using survey data (with self-reported measures) there is a chance that students might miss-reported about their smoking behavior. Future studies should use the best aspects from the methodology by Bewley and Bland [8] and Shahtahmasebi and Berridge [12].

There is a need for introducing anti-smoking campaigns for adolescences in schools at the government level. In addition, there is a need for counselling with parents about how the loneliness and smoking by family members may affect a child's attitude towards smoking.

\section{Acknowledgment}

We would like to thank Qatar University for giving us this opportunity and funding this project (QU-STCAS Fall 15/16-27). We would specially like to thank College of Arts and Science, Department of Mathematics, Statistics and Physics for providing us with sufficient help throughout the research.

\section{Funding}

The publication of this article was funded by the Qatar National Library. 


\section{References}

[1] Centers for Disease Control and Prevention. Preventing tobacco use among young people: a report of the Surgeon Ceneral (Executive Summary). Morb Mortal Wkly Rep. 1994;43(No. RR-4):5-6.

[2] DuRant R, Krowchuk D, Kreiter S, Sinal S, Woods C. Weapon carrying on school property among middle school students. Arch Pediatr Adolesc Med. 1999;153(1):21-6.

[3] Guller L, Zapolski TC, Smith GT. Longitudinal test of a reciprocal model of smoking expectancies and smoking experience in youth. Psychol Addict Behav. 2015;29(1):201-10.

[4] Evers S, Taylor ], Manske S, Midgett C. Eating and smoking behaviours of school children in southwestern ontario and charlottetown, PEI. Can ] Public Health. 2001;92(6):433-6.

[5] Kobus K. Peers and adolescent smoking. Addiction. 2003;98:37-55.

[6] Ali M, Dyer D. Estimating peer effects in adolescent smoking behaviour: alongitudinal analysis. ] Adolesc Health. 2009;45(4):402-4.

[7] Wileyto P, O'Loughlin ], Lagerlune M, Meshefedjian C, Dugas E, Cervais, A. Distinguishing risk factors for the onset of cravings, withdrawal symptoms and tolerance in novice adolescent smokers. Tob Control. 2009;19(5):387-92.

[8] Bewley B, Bland ]. Academic performance and social factors related to cigarette smoking by schoolchildren. ] Epidemiol Community Health. 1977;31:18-24.

[9] Country Fact Sheet - Qatar. 2016. Retrieved from http://www.tobaccoatlas.org/country-data/qatar.

[10] Clobal School-based Student Health Survey. Qatar 2011 Fact Sheet. (2011). Retrieved from http://www.who.int/chp/gshs/Qatar_CSHS_FS_2011.pdf?ua=1.

[11] Shocking finding about smoking prevalence in Qatar. (2014, September 21). Retrieved from http://www.gulftimes.com/Mobile/Opinion/189/details/409174/Shocking-finding-about-smoking-prevalence-in-Qatar.

[12] Shahtahmasebi S, Berridge D. Teenage smoking: a longitudinal analysis. Int ] Adolesc Med Health. 2005;17(2):137-56.

[13] Hosmer DW, Lemeshow S. Applied logistic regression. New York: John Wiley \& Sons, 2000.

[14] Chua YP. Statistik Penyelidikan Lanjutan Ujian Regresi, Analisis Faktor dan Ujian SEM. McGraw-Hill Malaysia, 2009.

[15] Aitkin M. Dealing with survey data. Brit ] Educ Psychol. 1979;49(2):198-205. 